Claremont Colleges

Scholarship@ Claremont

Pitzer Faculty Publications and Research

Pitzer Faculty Scholarship

8-1-2009

\title{
Probing Predispositions: The Pragmatism of a Process Perspective
}

David S. Moore

Pitzer College

\section{Recommended Citation}

Moore, David S. "Probing Predispositions: The Pragmatism of a Process Perspective." Child Development Perspectives 3.2 (2009): 91-93.

This Article - postprint is brought to you for free and open access by the Pitzer Faculty Scholarship at Scholarship @ Claremont. It has been accepted for inclusion in Pitzer Faculty Publications and Research by an authorized administrator of Scholarship @ Claremont. For more information, please contact scholarship@cuc.claremont.edu. 
Running head: Probing Predispositions

The content of this open-access post-print article is the same as that contained in the published article with the following reference:

Moore, D. S. (2009). Probing predispositions: The pragmatism of a process perspective.

Child Development Perspectives, 3, 91 - 93.

Probing Predispositions: The Pragmatism of a Process Perspective

David S. Moore

Pitzer College and Claremont Graduate University

May 13, 2008 


\begin{abstract}
As J. P. Spencer et al. (2009) argue, the theories of some developmental psychologists continue to be nativistic, even though nativism is an inherently nondevelopmental school of thought. Psychologists interested in development study the emergence of human characteristics - including predispositions - and are not content to simply catalogue competences that characterize human newborns; instead, they recognize that all human characteristics, including those present at birth, reflect the circumstances of development. A truly developmental science of behavior requires rejecting the nativism-empiricism debate outright, abandoning ideas such as "core knowledge"' and psychological “'endowments,', and adopting a process perspective that focuses on how traits emerge from the co-actions of biological and experiential factors. Unlike nativism, the process perspective advocated by J. P. Spencer et al. encourages research that can reveal the developmental origins of psychological characteristics of interest.
\end{abstract}


Probing Predispositions: The Pragmatism of a Process Perspective

In "Short arms and talking eggs: Why we should no longer abide the nativistempiricist debate," Spencer et al. (2009) criticize several constructs—e.g., "endowments, primitives, core knowledge, essences"- that some psychologists employ in spite of advances in developmental science suggesting they are not helpful. In particular, they criticize Spelke \& Kinzler (2007), who appear to seek middle ground in the empiricistnativist debate by arguing that the human mind is neither "a single general-purpose learning system" nor made of "myriad special-purpose systems and predispositions," but rather is composed of "a small number of separable systems of core knowledge" (p. 89).

Although Spencer et al. frame their discussion as a reaction, in part, to Spelke \& Kinzler's nativism, it is worth noting that Spelke \& Kinzler do not explicitly use some of the concepts that Spencer et al. find problematic. For example, Spencer et al. criticize the nativist notion of "relevant experience," but Spelke \& Kinzler never use this concept explicitly (and they use it implicitly only once, when discussing Valenza et al., 2006). Likewise, Spelke \& Kinzler do not explicitly label any behaviors “innate," even though nativists typically refer to at least some behaviors in this way. Nevertheless, Spencer et al. have not created a straw man; the nativist conceptions that concern them characterize the works of many psychologists, Spelke \& Kinzler included. For example, despite Spelke \& Kinzler's rejection of "single general-purpose" and "myriad special-purpose" views of the mind, their claim that people are "endowed" with "separable systems of core knowledge" clearly bears a close resemblance to the modern-nativist tenets that human minds have been shaped by evolution ("endowed") and are modular ("separable systems"). 


\section{Spelke \& Kinzler reject evolutionary psychologists' theories of massive} modularity, but their nativism is nonetheless evident in their notion of "core knowledge." It appears they consider knowledge systems to be "core" if they have phylogenetic roots and can be detected in infants. Thus, they believe there is something special about characteristics present in infancy; in fact, in an early paper on "core knowledge," Spelke (2000) wrote that cognitive systems that are "building blocks" for complex cognitive skills "may be especially amenable to study in infants, where they appear in relatively pure form" (p. 1241). However, the systems perspective increasingly favored by developmentalists (Gottlieb, 2007; Lickliter \& Honeycutt, 2003; Oyama, Griffiths, \& Gray, 2001) holds that traits that characterize infants are no more "pure" than other traits, because all traits emerge from developmental processes. In contrast, the idea that traits present in infancy provide privileged insight into "human nature" is quintessentially nativistic.

Nativists typically assume neonatal characteristics are "pure" because newborns have not had certain experiences ${ }^{1}$ (e.g., exposure to patterned light). However, a discovery indicating that a competence develops even without particular experiential input cannot support positive claims about the competence's origins. As Lehrman (1953) realized a half-century ago, we cannot infer that a competence is "innate" just because it develops in the absence of particular experiences; at best, such findings illuminate which

\footnotetext{
${ }^{1}$ Surprisingly, Spelke \& Kinzler (2007) argue that 3-month-olds' "visual preference for members of their own race" (p. 92) reflects the operation of a "core knowledge system," even though this bias requires specific experiences to develop. Consequently, it is not clear why the early appearance of such a bias renders it "core"; other psychological traits - the ability to read, for example-emerge after exposure later in life to particular stimuli, but no one argues that such traits somehow signal "core" knowledge.

Furthermore, the idea that racial biases have "evolutionary roots" is unsubstantiated in this paper, other than by reference to the speculative musings of some evolutionary psychologists. Without well-defined criteria for designating "knowledge systems" as "core," it is unclear why we should think racial biases are any more "core" than biases without phylogenetic roots or early appearances in infancy.
} 
experiential factors do not contribute to its development. The question of which experiential factors do contribute remains unanswered without further developmental analysis. Although intuition suggests that experience with patterned light should influence object-boundary perception, for example, we cannot know which experiential factors are influential before probing development; as Spencer et al. note, characteristics often develop only after organisms have particular experiences not obviously relevant to the characteristics' development.

If a competence or predisposition is found in infancy, scientists with a genuinely developmental orientation ask "from whence did this competence or predisposition emerge?" Among the things developmentalists do not conclude from such discoveries are a) that the competence or predisposition was pre-specified - in the genome or anywhere else - in a way that allowed it to develop independently of the context in which it emerged, b) that it is an "endowment" indicative of a particular phylogenetic history, or c) that it has some privileged "core" status relative to later-developing abilities (the ability to read, for example) that other skills or beliefs can be built on. Developmentalists refrain from the latter conclusions because they are mere speculations. They refrain from the first conclusion because human characteristics never emerge independently of developmental circumstances. Among the most important discoveries of modern developmental science has been the finding that genes are expressed in epigenetic contexts that profoundly influence development (Harper, 2005; Jablonka \& Lamb, 2005; Weaver et al., 2007) and that species-typical brain structures, likewise, often reflect the contexts — both pre- and post-natal—in which development occurs (Johnson, 2005). 
Developmentally-oriented scientists are interested not in the number or nature of human predispositions, but in their origins, because like all characteristics, predispositions must develop; they cannot be genetically specified or emerge independently of development (Moore, 2001). Even cross-cultural or cross-species universals like Spelke \& Kinzler's “endowments” develop, via processes that are dynamic and interactive (Thelen \& Smith, 1994). This insight spurs researchers to probe the process by which predispositions (or competences or any other traits) develop. Thus, process approaches are pragmatic; they encourage research on a predisposition's origins, which could reveal how to influence its development. In contrast, claims that infants are born with a predisposition seem to answer a question about origins, but they actually do not. Identifying early-appearing proclivities and labeling them "core"-a designation implying they are somehow 'atomic' and not subject to further analysis - effectively short-circuits developmental investigation, halting the scientific pursuit of understanding (Lehrman, 1953). The value of a process approach was obvious to embryologist Wilhelm His 120 years ago, when he wrote:

“...The single word 'heredity' cannot dispense science from the duty of making every possible inquiry into the mechanism of organic growth...To think that heredity will build organic beings without mechanical means is a piece of unscientific mysticism...A direct explanation...[of trait emergence] can only come from the immediate study of the different phases of individual development..." (His, 1888, p. 295).

The same could be written of the words "endowed" or "core." 
Thus, the real insight of developmental science has been the realization that the empiricist-nativist debate cannot be resolved by agreeing that the truth lies somewhere between poles staked out by empiricists and nativists; instead, developmental research indicates that the debate itself should be rejected outright, as a conversation generated in response to a poorly formed question, namely, whether human nature is learned or inherited. Focusing on developmental origins reveals that traits develop from complex interactions involving the participation of factors - including both genetic and nongenetic factors operating at all levels of organization - that cannot be understood in terms of older conceptions of inheritance or learning. Developmental systems theorists have discovered that experiences often influence development in ways that bear little resemblance to well-characterized modes of learning, and that organisms "inherit" from their ancestors both biological and non-biological contributors to development (Oyama et al., 2001). Consequently, Spencer et al.'s (2009) concerns about claims that appear to resolve the empiricist-nativist debate are justifiable.

Spencer et al. effectively critique nativism, but they do not embrace empiricism; they never argue that evolutionary accounts are valueless in attempts to explain human cognition or that "a single learning system" can explain all psychological phenomena. Instead, they reject the empiricism-nativism debate entirely. But unlike Spelke \& Kinzler, who claim to seek resolution while still promulgating nativism, Spencer et al. reject the debate by suggesting we stop asking whether or not experiences contribute to development, and ask instead how traits emerge from the co-actions of the biological and experiential factors that together comprise the complex developmental systems we are. 


\section{References}

Gottlieb, G. (2007). Probabilistic epigenesis. Developmental Science, 10, 1 - 11.

Harper, L. V. (2005). Epigenetic inheritance and the intergenerational transfer of experience. Psychological Bulletin, 131, 340 - 360.

His, W. (1888). On the principles of animal morphology. Proceedings of the Royal Society of Edinburgh, 15, 287 - 298.

Jablonka, E., \& Lamb, M. J. (2005). Evolution in four dimensions: Genetic, epigenetic, behavioral, and symbolic variation in the history of life. Cambridge, MA: MIT.

Johnson, M. H. (2005). Developmental Cognitive Neuroscience, (2nd ed.). Malden, MA: Blackwell Publishing Ltd.

Lehrman, D. S. (1953). A critique of Konrad Lorenz's theory of instinctive behavior. The Quarterly Review of Biology, 28, 337-363.

Lickliter, R., \& Honeycutt, H. (2003). Developmental dynamics: Toward a biologically plausible evolutionary psychology. Psychological Bulletin, 129, 819 - 835.

Moore, D. S. (2001). The dependent gene: The fallacy of nature vs. nurture. New York: W.H. Freeman.

Oyama, S., Griffiths, P. E., \& Gray, R. D. (Eds.) (2001). Cycles of contingency: Developmental systems and evolution. Cambridge, MA: MIT.

Spelke, E. S. (2000). Core knowledge. American Psychologist, 55, 1233 - 1243.

Spelke, E. S., \& Kinzler, K. D. (2007). Core knowledge. Developmental Science, 10, 89 - 96.

Spencer, J. P., Blumberg, M. S., McMurray, B., Robinson, S. R., Samuelson, L. K., \& Tomblin, J. B. (2009). Short arms and talking eggs: Why we should no longer abide the nativistempiricist debate. Child Development Perspectives, 3, 79 - 87.

Thelen, E., \& Smith, L. B. (1994). A dynamic systems approach to the development of cognition and action. Cambridge, MA: MIT Press.

Valenza, E., Leo, I., Gava, L., \& Simion, F. (2006). Perceptual completion in newborn human infants. Child Development, 77, 1810 - 1821.

Weaver, I. C. G., D’Alessio, A. C., Brown, S. E., Hellstrom, I. C., Dymov, S., Sharma, S., et al. (2007). The transcription factor nerve growth factor-inducible protein A mediates epigenetic programming: Altering epigenetic marks by immediate-early genes. The Journal of Neuroscience, 27, $1756-1768$. 